\title{
A computational simulation of the motion of floating wind turbine platforms
}

\author{
A. Nematbakhsh ${ }^{1}$, D. J. Olinger ${ }^{1} \&$ G. Tryggvason ${ }^{2}$ \\ ${ }^{1}$ Mechanical Engineering Department, \\ Worcester Polytechnic Institute, USA \\ ${ }^{2}$ Department of Aerospace and Mechanical Engineering, \\ University of Notre Dame, USA
}

\begin{abstract}
The dynamic motion of floating wind turbines is studied using numerical simulations. The full Navier-Stokes equations are solved on a regular structured grid, using a level set method for the free surface and an immersed boundary method to model the turbine platform. The response of a tension leg platform to moderate amplitude waves is examined and the effect of a key design parameter is quantified in this initial study. It is shown that the pitch and surge motion amplitudes are larger than heave motions, and that increased ballast weight helps to stabilize the platform motions and reduce tether tensions.

Keywords: floating wind turbines, numerical simulation, fluid-structure interaction, level-set methods.
\end{abstract}

\section{Introduction}

Using wind to produce electricity is attractive since wind resources are relatively plentiful, the basic technology is well developed and it is rapidly becoming economically competitive with conventional carbon based electricity production. As its use has grown, however, concerns have emerged. Places best suitable for land-based wind-turbines, such as the plains of the midwest United States, are often located far from densely populated areas along the coasts; and a nonnegligible fraction of the population objects to the visual impact of wind-turbines on beaches, mountaintops, and most places in between. Placing floating wind turbines far offshore avoids most of these concerns. The wind is usually stronger and steadier, and the potential negative impact of the turbines is minimal. 
While many near-shore, bottom mounted, wind turbines have been constructed in Europe, interest in floating turbines required at ocean depths greater than 50 meters, is much more recent. Only two large-scale prototypes have been built so far, one by Statoil called Hywind, deployed off the coast of Norway, and the other by Blue H, tested off the coast of Italy. These installations use turbine platforms that are taken largely from the oil and gas industry, and shown in Figure 1. The Hywind turbine sits on a spar buoy, consisting of a single cylinder of approximately $100 \mathrm{~m}$ draft and $10 \mathrm{~m}$ diameter. Spar buoys are stabilized with added ballast at the bottom of a large aspect ratio (draft/diameter) cylinder. The mooring system for spar buoys usually consists of slack or ballasted catenary cables that are used for station-keeping. Another proposed concept is the tension leg platform (with a smaller cylinder aspect ratio) where vertical, tensioned underwater cables provide the restoring moments for stability.

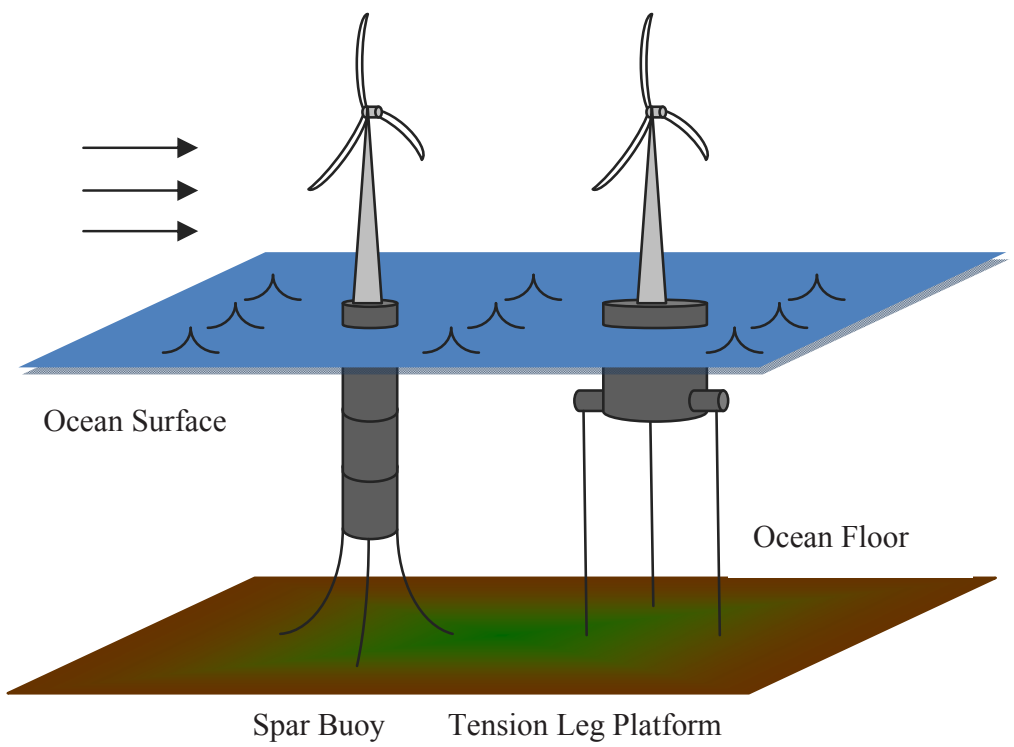

Figure 1: $\quad$ Floating wind turbine concepts (not to scale).

Floating wind turbines were first envisioned by Heronemus [1], however it was not until the commercial wind industry was well established in the mid1990's that the topic was given further attention in Refs. [2-7], which examined various aspects of the feasibility, design, and economics of the concept. The overall findings of these studies is that floating turbines are technically feasible with existing or near-term technology, that some design challenges still exist, and that reducing platform and mooring system costs is critical for economic viability.

While there has been a preponderance of economic, design, and feasibility studies, the economics of floating wind turbines are strongly linked to platform and mooring system design and costs, which are in turn dependent on the 
detailed motion of the coupled platform, turbine, and mooring system. Studies focused on modeling these motions are relatively recent, and have generally used either linear frequency-domain (LFD) analysis or time-domain dynamics (TDD) models, as summarized in Jonkman [8]. These models often employ developed simulation tools [9-12]. A summary of work using these models follows.

Studies [13-17] that predicted the aeroelastic, hydrodynamic, and rigid body motion responses of floating wind turbines have been used to investigate various platform and mooring arrangements. References [8, 18, 19] summarize the development of simulation tools that include models of aerodynamic, gravitational, and inertial loading of the rotor, nacelle, and tower; elastic structural effects; wave loading; dynamic loading between the platform and turbine; and motions of the mooring cables. Recently, Karimirad [20] studied the dynamic response of floating structures to extreme wave and wind loads.

The linear frequency-domain (LFD) and time-domain dynamics (TDD) models generally used in the above studies have limitations as summarized in [8]. The LFD models cannot capture the non-linear dynamic characteristics and transient events important for wind turbine analysis. The TDD models are often not general enough to allow analysis of a variety of platform configurations. The potential flow theory used in these models assumes that the flow is inviscid and irrotational, and subject only to conservative body forces. The linearized TDD models are limited to incident wave amplitudes that are much smaller than their wavelengths. This precludes modeling of steep or breaking waves, and wave loading for extreme waves. Linearization also implies that the motions of the support platform are small relative to the characteristic body length. The models also ignore loading from vortex-induced vibration caused by sea currents.

To help overcome these limitations, we seek to develop three-dimensional computational methods utilizing the fully non-linear, viscous Navier-Stokes equations. Such a formulation will in particular, allow modeling of largeamplitude waves that result in maximum structural loading which can often drive system design decisions. Previous computational studies on floating wind platforms are rare. Chexoxarov [21] investigated wind loading on a floating turbine rotor, including the effect of wind velocity and turbine rotation rate, by solving the three-dimensional Navier-Stokes equations with using finite volume methods. Although computational studies of the dynamics of floating wind turbines are rare, floating platforms for oil and gas production have been examined in some detail (Chiu [22]). Fonseca et al. [23] provides an overview of the modeling of tethered floats. An example of a recent computational study, representing the state-of-the-art, can be found in Bai and Taylor [24].

In most of the studies referenced above, the focus has been on a fixed geometry proposed as a conceptual design for a floating wind turbine platform. Studies which systematically vary key physical and geometric parameters (such as ballast weight, ballast volume, tower weight, for example) have rarely been conducted. Design variations such as this can most easily be studied using computational simulations. Here, we describe an initial computational study of the response of tension leg platforms with vertical tethers to moderate amplitude waves. In order to show that the developed computational model can be used to 
study the effect of varying important design variables, we systematically vary ballast weight, and study the effect on platform dynamics. The paper is organized as follows. In section 2 the computational model is summarized by describing the governing equations of motion, numerical methods, boundary conditions, numerical grid refinement, and validation methods. In the results section, a baseline case for a 100:1 scale-model turbine platform in a wave tank is studied. Platform dynamics (surge, pitch) and tether tensions are summarized for various ballast weights. Conclusions are presented in Section 4.

\section{Computational model and problem setup}

The computations are done using a three dimensional rectangular domain that the whole flume, including both the water and the air. The domain is resolved by a regular structured grid, stretched to allow us to cluster grid points around the turbine. At the upstream end waves are generated by specifying the inlet velocities using a second order Stokes flow solution and fluid is allowed to flow in and out through the top to match the velocity specified by the wave maker. Full slip boundary conditions are imposed on all other sides of the flume. At the other end of the domain the grid is coarsened to damp out the waves. The turbine is located relatively close to the wave maker; slightly less than two wavelengths from the boundary $(1.25 \mathrm{~m})$. The turbine is attached to the bottom of the flume by four pretensioned tethers. Figure 2 shows the domain and the location of the turbine. The computational model consists of the flow solver; the tracking of the free surface, and the tether model.

The fluid flow is described by the "one-fluid" Navier-Stokes equations, where one set of equations is used for the whole domain and the different fluids are identified by the different material properties. The momentum equations

$$
\frac{\partial \mathbf{u}}{\partial t}+\nabla \cdot(\mathbf{u u})=\frac{-1}{\rho} \nabla p+\frac{1}{\rho} \nabla \cdot\left(\nabla \mathbf{u}+\nabla \mathbf{u}^{T}\right)+\mathbf{g}
$$

are supplemented by the continuity equation;

$$
\nabla \cdot \mathbf{u}=0
$$

These equations are solved by an explicit second order predictor corrector method on a staggered grid. The advection terms are discretized using a second order ENO method and a simple second order centered difference approximation is used for the viscous terms. The pressure equation is solved using a simple iterative method.

To track the free surface, a level set method is used [25]. The level set function is advected using a predictor corrector ENO method and reinitialized by a few iteration in fictitious time to maintain it as a distance function. For details see [26] and [27]. Once the level set function has been updated, the density and viscosity are adjusted to match the new free surface position. 


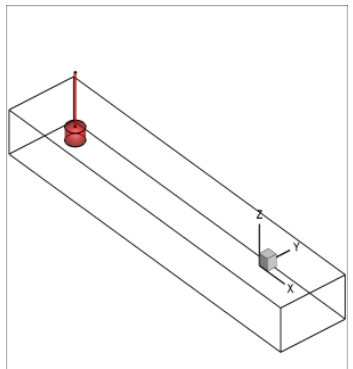

(a)

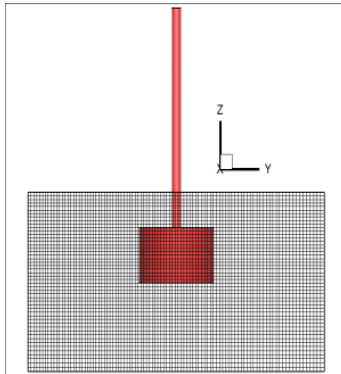

(b)

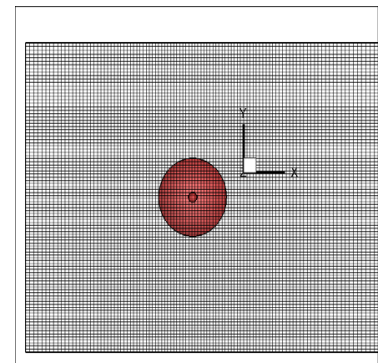

(c)

Figure 2: (a) Three-dimensional view of numerical domain, (b) front view; (c) top view of refined grid near cylinder. The numerical grid extends from $-1.25 \mathrm{~m}<\mathrm{x}<8.75 \mathrm{~m},-1 \mathrm{~m}<\mathrm{y}<1 \mathrm{~m}, 0 \mathrm{~m}<\mathrm{z}<1 \mathrm{~m}$.

To track the solid body, a marker function is defined to identify the solid region.

$$
C= \begin{cases}1 & \text { inside the solid } \\ 0 & \text { outside the solid }\end{cases}
$$

In order to calculate the velocity of the solid, the Navier-Stokes equations are solved in the whole domain, including in the region occupied by the solid body. The find the velocity in the solid, we first find the linear and angular momentum of the solid by integrating the velocity found by the solution of the Navier-Stokes equations inside the solid:

$$
\begin{gathered}
M_{\text {solid }} \mathbf{V}_{\text {solid }}=\int_{\Omega} C \rho_{S} \mathbf{v} d \Omega \\
{[I] \omega=\int_{\Omega} \mathbf{r} \times C \rho_{S} \mathbf{v} d \Omega}
\end{gathered}
$$

where

$$
[I]=\left[\begin{array}{ccc}
I_{x x} & -I_{x y} & -I_{x z} \\
-I_{y x} & I_{y y} & -I_{y z} \\
-I_{z x} & -I_{z y} & I_{z z}
\end{array}\right] \text { and } \quad \omega=\left[\begin{array}{c}
\omega_{x} \\
\omega_{y} \\
\omega_{z}
\end{array}\right]
$$

Here, $M_{\text {solid }}$ is the mass of the solid, and $\mathbf{V}_{\text {solid }}$ is center of mass velocity of the solid, $\rho_{S}$ is local density of the solid, $\mathbf{V}$ is the local solid velocity and $\Omega$ is the volume of the solid. [I] is the symmetric moment of inertial matrix for the solid and $\omega$ is the angular velocity of the solid. After the center of mass 
velocity and the angular rotation have been found, the location of the solid and the velocity in the solid can be corrected. Since the original velocity field and the corrected velocity in the solid are both divergence free, the new velocity field should be divergence free. In practice the velocity may be not completely divergence free near the solid surface. If desired, it is possible to recompute the pressure and correct the velocity again. For details see Yabe et al. [28] and Sharma and Patankar [29].

Vertical pretensioned tethers are used in order to restrict the motion of the floating wind turbine. Here we assumed extensible tethers and a simple Hooke's law for calculating the tether forces on the solid. Hydrodynamic forces on the tethers or the turbine tower are not currently modelled.

The model described above, including the level set method for tracking the free surface flow, has been validated by modelling a standing wave in a twodimensional rectangular domain with an initial sine function shape. In Figure 3 we show the numerical results for a decaying wave (due to the effects of viscosity). The results are in good agreement with an exact solution from [30].

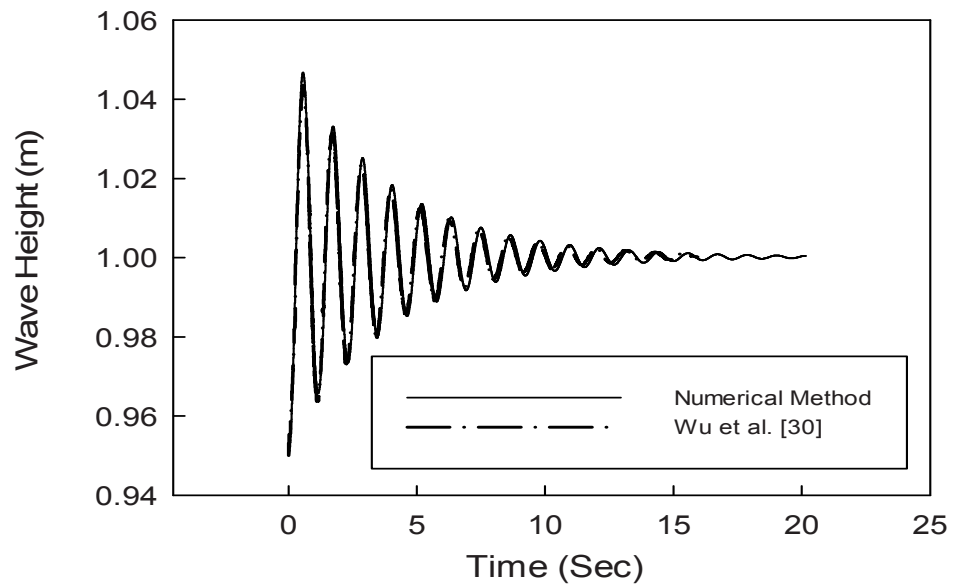

Figure 3: Comparison of the numerical method with an exact solution for free surface flow.

A grid refinement study was conducted on a two-dimensional rectangular domain with uniform grid spacing, $4 \mathrm{~m}$ long by $2 \mathrm{~m}$ height with $1.5 \mathrm{~m}$ water depth. The rectangular platform structure ( 0.5 meter length $\mathrm{x} 0.3 \mathrm{~m}$ height) is freely floating, and the underwater cables are not modelled. Figure 4 shows solutions for the surge motion S/D that are nearly converged for a $320 \times 160$ grid. As a result, a $200 \times 100 \times 50$ grid is used for the three-dimensional simulations as shown in Figure 2. 


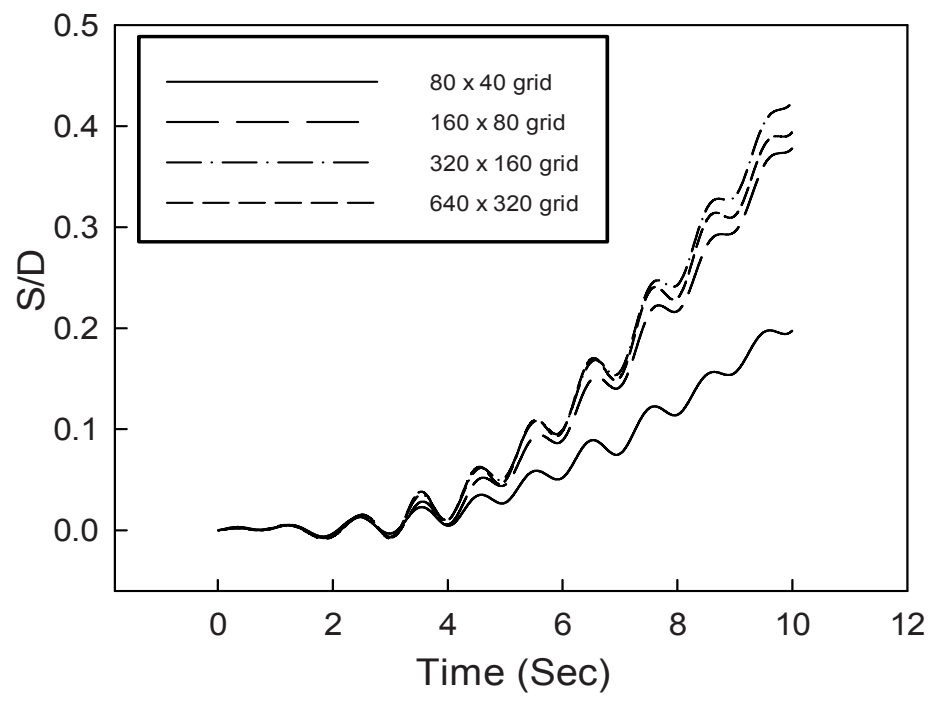

Figure 4: Grid refinement study. Surge displacements.

\section{Results}

\subsection{Baseline simulation}

The goal here is to examine the dynamics of the tension leg platform shown in Figure 1 when exposed to moderate amplitude wave loading. In Figure 5 we show several frames from a baseline simulation. A 100:1 scale-model floating wind turbine platform is modeled in this study. A scale-model is chosen, as opposed to a full-scale platform, since the authors are also conducting scalemodel experiments in a wave tank. Future publications will compare the numerical simulations and experiments. The baseline simulation is conducted in a rectangular domain (flume) with $10 \times 2 \times 1$ meter length, width and height respectively, with water height set at 0.7 meter. The length of the domain is long enough in order to prevent the effects of reflecting waves.

The floating object in Figure 5 is a partially submerged cylinder of $\mathrm{D}=0.5 \mathrm{~m}$ diameter, $\mathrm{H}=0.3 \mathrm{~m}$ height, and $.204 \mathrm{~m}$ draft, with an attached tower. The baseline simulation uses a ballast weight of $31.8 \mathrm{~kg}$, the center of gravity is located $0.054 \mathrm{~m}$ below the free surface, and the metacentric height is $-0.029 \mathrm{~m}$, making the platform unstable without the presence of vertical cables as often occurs for tension leg platforms. The uniform density ballast weight encompasses the entire height of the circular tank. The tower and cylinder structure are considered massless in this initial study, so that ballast weight constitutes the entire structure weight. The wave maker generates stationary waves with wave length equal to 0.7 meter, period of 0.695 seconds, and wave heights of 0.06 meter. A second-order Stokes theorem is used for generating 
waves. Four vertical tethers restrain the motion of floating object. The four tethers are equally spaced around the circumference of the platform tank $\left(90^{\circ}\right.$ apart), and all tethers are located $45^{\circ}$ from the tunnel centerline. The tether axial stiffness $\left(10^{4} \mathrm{~N} / \mathrm{m}\right)$ is set to match the scale-model tether (nylon) stiffness. A tether pretension of about $5 \%$ of total weight of the structure is applied. The simulation is run for 15000 time step ( 15 seconds).

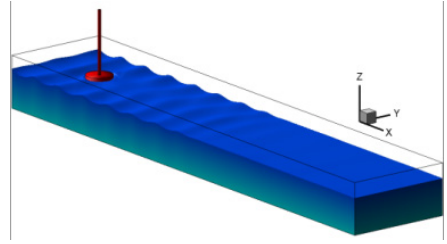

(a)

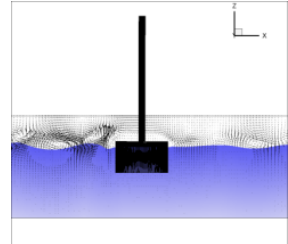

(b)

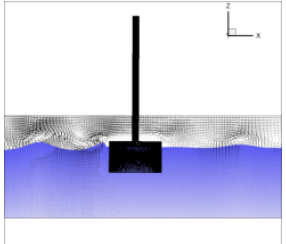

(c)

Figure 5: Simulation of scale-model floating wind turbine platform, baseline run. (a) Three-dimensional simulation showing wave heights. $(\mathrm{t} / \mathrm{T}=$ 17.27). (b), (c) Two-dimensional view (cylinder midplane) at $\mathrm{t} / \mathrm{T}$ $=9.21, \mathrm{t} / \mathrm{T}=9.78 \mathrm{~s}$ showing velocity vectors as incident wave passes front and rear of cylinder.

In Figure 5, vortex motions consistent with moderate amplitude waves passing the cylinder are observed near the free surface in both the air and water. The platform motions observed in Fig. 5 are quantified next. The platform's horizontal (surge) displacements $\mathrm{S}$, pitch motions (in $\mathrm{x}-\mathrm{Z}$ plane) and tether tensions vs. time are shown in Figure 6. Sway, heave, roll, and yaw motion amplitudes are all at least one order of magnitude smaller than the surge and pitch motions, and will not be presented here. The platform initially surges downstream due to the incident waves (displacement $\sim 10 \%$ of the tank diameter), and then settles into a periodic surge oscillation at near the wave frequency. The platform pitches between approximately $\pm 0.28^{\circ}$, also at the wave frequency. Upstream tether tensions are larger than downstream tether tensions as expected due to the surge motion. For a 100:1 scale platform, there is a $10^{6}: 1$ ratio in tension force between the full-scale and model.

\subsection{Ballast weight variation}

To examine the effect an important design variable we have varied the ballast weight of the platform over the range $32-42 \mathrm{~kg}$. The center of gravity of the platform is situated between 0.05 to $0.10 \mathrm{~m}$ below the top of the tank, the draft varies from 0.2 to $0.25 \mathrm{~m}$, and the metacentric height from -0.029 to $-0.007 \mathrm{~m}$ as the ballast weight is varied. The cable pretension is held constant when the ballast weight is varied. In Figure 7, the variation of maximum surge displacements, maximum pitch angles, and upstream tether tensions as a function of ballast weight are shown. It is shown that platform motions, along with upstream tether tensions, are reduced by up to $10-20 \%$ as ballast weight is increased by $30 \%$. 

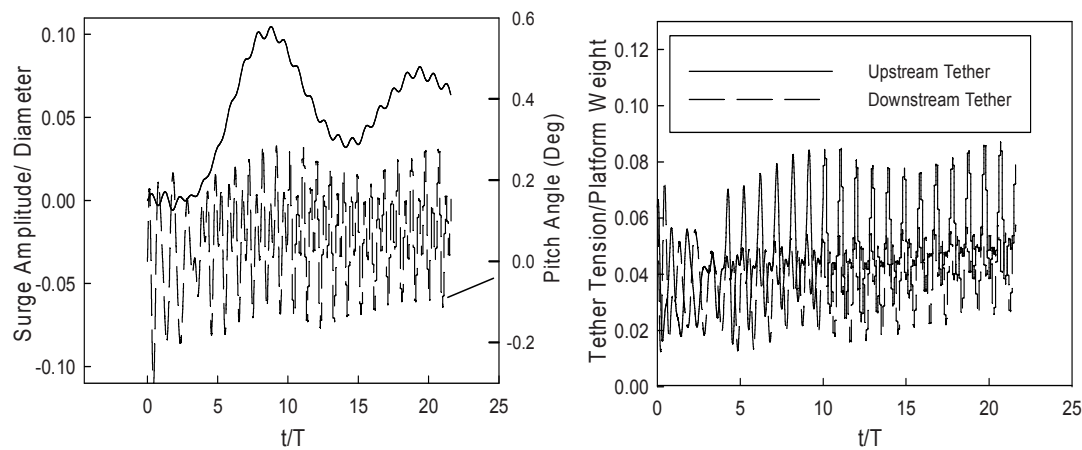

Figure 6: $\quad$ Surge, pitch motions and tether tensions for the baseline case.
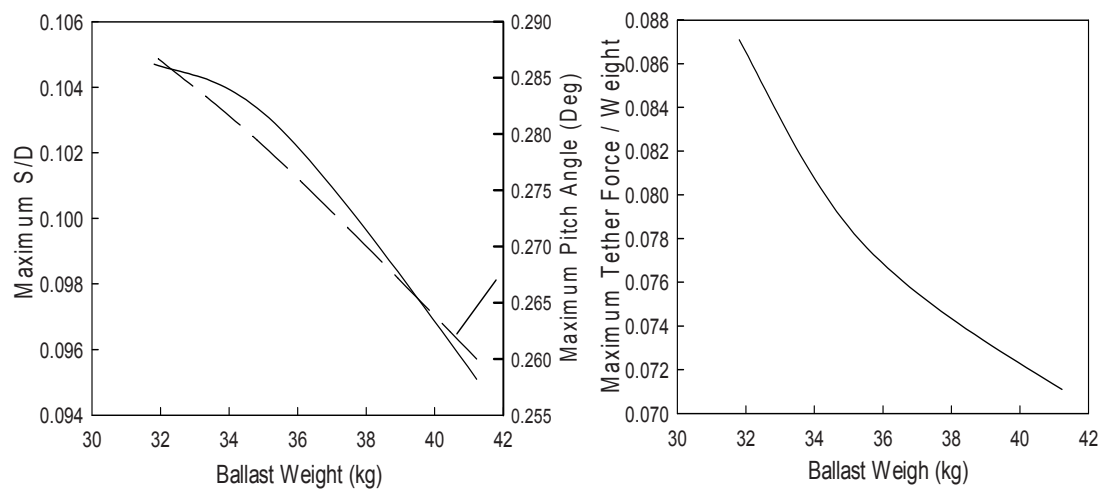

Figure 7: Maximum surge displacements, pitch angles, and upstream tether forces as ballast weight is varied.

\section{Conclusion}

The computational model utilizing the fully viscous Navier-Stokes equations developed here has allowed us to examine the effect of design changes on the response of a tension leg platform in a very cost effective way. The results show, perhaps not surprisingly, that a platform with larger ballast and attached vertical tethers provides the most stable platform. Key parameters such as tank diameter and draft, tether attachment points, and wave height and frequency have been kept constant in this initial study. A study of how these variables affect the platform dynamics will be reported elsewhere, along with the effect of nonperiodic waves using response amplitude operators. Although floating wind turbines are currently being designed and built on platform using technology directly from the offshore oil and gas industry, we believe that the much smaller scale and stringent economic requirements for wind turbines is likely to eventually result in platforms that may be significantly different than those used 
for oil and gas extraction. The study described here has developed computational tools to examine the effect of moderate amplitude waves on a floating platform, and how it can be used to examine the effect of the various design parameters.

\section{References}

[1] Heronemus, W.E., Power from offshore winds. Proc. of the 8th Annual Conference and Exposition on Applications of Marine Technology to Human Needs, pp. 535-466, 1972.

[2] Tong, K. \& Cannell, C., Technical and economical aspects of a floating offshore windfarm. Wind Engineering, 17, pp. 108-112, 1993.

[3] Henderson, A.R. \& Patel, M.H., On the modeling of a floating offshore wind turbine. Wind Energy, 6, pp. 53-86, 1998.

[4] Ushiyama, I., Seki, K. \& Miura, H., A feasibility study for floating offshore windfarms in Japanese waters. Wind Engineering, 28, pp. 383397, 2004.

[5] Butterfield, S., Musial, W., Jonkman, J. \& Sclavounos, P., Engineering challenges for floating offshore wind turbines. NREL/CP-500-38776, 2007.

[6] Musial W., Butterfield, S. \& Boone, A., Feasibility of floating platform systems for wind turbines. NREL/CP-500-34874, 2003.

[7] Sclavounos, P., Floating offshore wind turbines. Marine Technology Society Journal, 42 (2), pp. 39-43, 2008.

[8] Jonkman, J.M., Dynamics of offshore floating wind turbines - model development and verification. Wind Energy, 12(5), pp. 459-492, 2009.

[9] Jonkman, J.M., \& Buhl, M.L., FAST User's Guide, NREL/EL-500-38230, 2005.

[10] Laino, D.J., \& Hansen, A.C., User's Guide to the Wind Turbine Dynamics Aerodynamics Computer Software - AeroDyn. Windward Engineering LLC: Salt Lake City, UT, 2002.

[11] Laino, D.J., \& Hansen, A.C., User's Guide to the Computer Software Routines AeroDyn Interface for ADAMS ${ }^{\circledR}$. Windward Engineering LLC: Salt Lake City, UT, 2001.

[12] Lee, C.H., \& Newman, J.N., WAMIT User Manual, Versions 6.3, 6.3PC, 6.3S, 6.3S-PC. WAMIT, Inc., Chestnut Hill, MA, 2006.

[13] Quarton, D., The calculation of design loads for offshore wind turbines. Wind Engineering, 21, pp. 267-279, 1997.

[14] Zambrano, T., MacCreedy, T., Kiceniuk, T., Roddier, D., \& Cermelli, C., Dynamic modeling of deepwater offshore wind turbine structures in Gulf of Mexico storm conditions. Proc. of the International Conference on Offshore Mechanics and Arctic Engineering- OMAE, 2006.

[15] Suzuki, H., \& Sato, A., Load on turbine blade induced by motion of floating platform and design requirement for the platform. Proc. of the International Conference on Offshore Mechanics and Arctic EngineeringOMAE, 5, pp. 519-525, 2007. 
[16] Bir, G., \& Jonkman, J., Aeroelastic instabilities of large offshore and onshore wind turbines. Journal of Physics: Conference Series, 75 (1), pp. 12-31, 2007.

[17] Tang, Y., Zhang, S., Zhang, R. \& Liu, H., Development of study on the dynamic characteristics of deep water mooring system. Journal of Marine Science and Application, 6, pp. 17-23, 2007.

[18] Jonkman, J.M., \& Sclavonous, P.D., Development of fully coupled aeroelastic and hydrodynamic models for offshore wind turbines. Proc. of the $44^{\text {th }}$ AIAA Aerospace Sciences Meeting, 16, 2006.

[19] Jonkman, J.M. \& Buhl, M.L., Loads analysis of a floating offshore wind turbine using fully coupled simulation. NREL/CP-500-41714, 2007.

[20] Karimirad, M., Dynamic response of floating wind turbines, Scientia Iranica, 17 (2), pp. 146-156, 2010.

[21] Chexoxarov, V.V., Calculation of wind loading on large-scale floating wind turbines. Pp. 216-221, 2004.

[22] Chiu, H., Offshore production systems for ultra-deep water in the Gulf of Mexico - Part I: Well systems. International Journal of Offshore and Polar Engineering, (2)4, pp. 241-250, 1992.

[23] Fonseca, N., Guedes Soares, C. \& Incecik, A., Numerical and experimental study of large amplitude motions of two-dimensional bodies in waves. Applied Ocean Research, 19, pp. 35-47, 1997.

[24] Bai, W. \& Taylor, E., Fully nonlinear simulation of wave interaction with fixed and floating flared structure. Ocean Engineering, 36, pp. 223-236, 2009.

[25] Osher, S.J., and Sethian, J.A., Fronts propagating with curvature dependent speed: algorithms based on Hamilton-Jacobi formulations. Journal of Computational Physics, 79, pp. 12-49, 1988.

[26] Sussman, M., and Fatemi, E., An efficient interface-preserving level set redistancing algorithm and its application to interfacial incompressible fluid flow. SIAM Journal of Scientific Computing, 20, pp. 1165-1191, 1999.

[27] Fedkiw, R.P. Aslam, T.; Merriman, B.; Osher, S. A non-oscillatory Eulerian approach to interfaces in multimaterial flows (the ghost fluid method), Journal of Computational Physics, 152, (2), pp. 457-92, 1999

[28] Yabe, T., Xiao, F., \& Utsumi, T., The constrained interpolation profile method for multiphase analysis. Journal of Computational Physics, 169, pp. 556-503, 2001.

[29] Sharma N, Patankar NA, A fast computation technique for the direct numerical simulation of rigid particulate flows, Journal of Computational Physics, 205, pp. 439-457, 2005.

[30] Wu, G.X., Taylor, R.E. \& Greaves, D.M., The effect of viscosity on the transient free-surface waves in a two-dimensional tank. Journal of Engineering Mathematics, 40, pp. 77-90, 2001. 